\title{
APORTES A LA DETERMINACIÓN DE PALEOAMBIENTES, CARBONES DEL SINCLINAL CHECUA-LENGUAZAQUE. COLOMBIA
}

\author{
(Contributions to determine paleoenvironments, coals syncline Checua- \\ Lenguazaque. Colombia)
}

\author{
Juan Sebastián Gómez Neita ${ }^{1}$, Mayra Dayana López Carrasquilla ${ }^{1}$, Sandra Rocio Manosalva Sánchez ${ }^{1}$, \\ Wilson Enario Naranjo Merchán ${ }^{1}$ \\ ${ }^{1}$ Escuela de Ingeniería de Geológica, Universidad Pedagógica y Tecnológica de Colombia, (Sogamoso-Boyacá, \\ Colombia). Grupo inv. Ingeniería Geológica, Juan.gomezneita@uptc.edu.co, Mayradayana.lopez@uptc.edu. \\ co, Sandra.manosalva@uptc.edu.co, Wilson.naranjo@uptc.edu.co
}

(Recibido marzo 29 de 2016 y aceptado mayo 27 de 2016)

\begin{abstract}
Resumen
El presente estudio, tuvo como objetivo realizar nuevos aportes al conocimiento e interpretación del paleoambiente de los carbones de la Formación Guaduas, de edad Maestrichtiano Superior a Paleoceno. Se realizó el análisis petrográfico de 64 muestras colectadas con el método de canal en tres secciones del sinclinal de Checua-Lenguazaque (Sutatausa, Guachetá y Samacá), estableciéndose que los carbones están compuestos principalmente por macerales del grupo de la vitrinita con porcentajes entre (51.4\% - 87\%), seguidos por los de la inertinita $(5.4 \%-43.8 \%)$, liptinita $(0.2 \%-14 \%)$, y materia mineral ( $0.4 \%$ - 18\%). La reflectancia media de la vitrinita varió de 0,69 a 1,6; con rango de carbones bituminosos $\mathrm{C}$ a bituminosos $\mathrm{A}$. La lectura maceral permitió determinar la distribución de los componentes orgánicos del carbón a fin de aplicar la metodología propuesta por Diessel (1992) y la usada por Singh \& Singh (2000) para la definición de paleoambientes; concluyéndose que los carbones de los bloques Guachetá y Samacá fueron depositados en ambientes de zonas protegidas por barreras y ciénagas principalmente, mientras que los carbones del bloque Sutatausa se extendieron hasta pantanos de bosque húmedo. La tabla de agua aunque variable cubría la turbera, lo cual favoreció la conservación de la materia orgánica frente a la oxidación.
\end{abstract}

Palabras claves: Facies de Carbón, maceral, paleoambientes, reflectancia de la vitrinita.

\begin{abstract}
This study aims to make new contributions to the knowledge and interpretation of paleoenvironment of Guaduas Formation's coals, Superior Maestrichtian to Paleocene age. Petrographic analysis of 64 samples collected them by the channel method in three sections of the Checua-Lenguazaque syncline (Sutatausa, Guachetá and Samacá), establishing that the coals are composed mainly of macerals of the vitrinite group with percentages between $(51.4 \%-87 \%)$, followed by the inertinite group $(5.4 \%-43.8 \%)$, liptinite $(0.2 \%-14 \%)$, and mineral matter $(0.4 \%-18 \%)$. The average vitrinite reflectance ranged from 0.69 to 1.6 ; showing bituminous coals $C$ to bituminous coals $A$. The maceral reading allowed the determination of the distribution of organic components of coal to implement the methodology proposed by Diessel (1992) and the used it by Singh \& Singh (2000), for the definition of palaeoenvironments; concluding that the coals of Guachetá and Samacá blocks were deposited in environments of protected areas for barriers and bogs mainly, while the coals of the Sutatausa block extended into wet-forest swamps. Table water although variable, covered the peat bog which favored the preservation of organic material against oxidation.
\end{abstract}

Keywords: Coal facies, maceral, palaeoenvironments, vitrinite reflectance. 


\section{INTRODUCCIÓN}

La Formación Guaduas es la unidad carbonífera de la zona centro de Colombia; datada de edad Maestrichtiano Superior a Paleoceno (Van Der Hammen, 1958; De Porta, 1974; Guatame et al., 2004). Presenta una dirección NE en el sinclinal Checua-Lenguazaque (Departamentos De Cundinamarca y Boyacá, Figura1) y varía de espesor según el bloque analizado, presentando un adelgazamiento hacia Samacá (Cooper et al., 2009). De acuerdo a los estudios estratigráficos realizados por (Sarmiento, 1992) se plantean cuatro horizontes de pantanos transgresivos relacionados con las 12 litofacies presentes en la unidad como describe (Amaya et al., 2010).

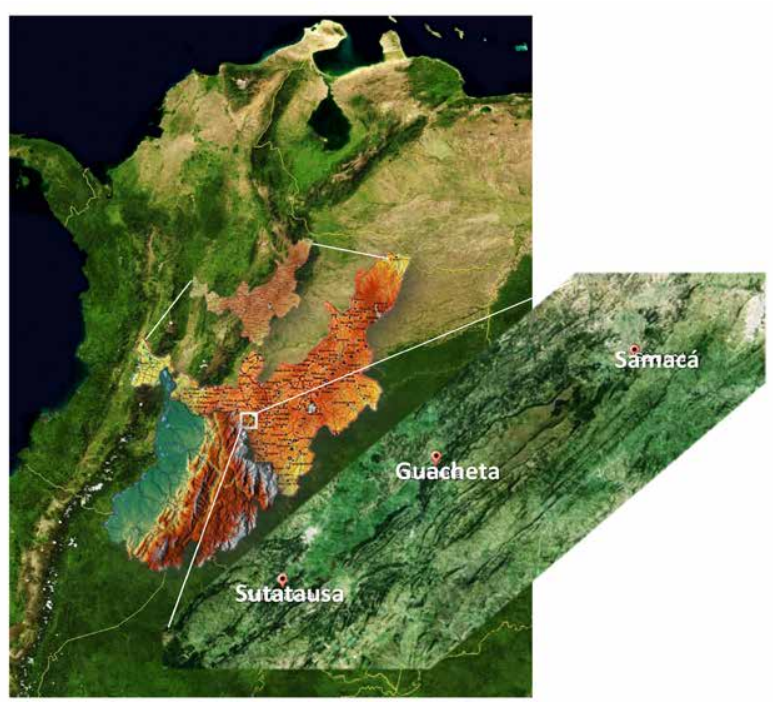

Figura 1. Ubicación del área de estudio.

El grado de carbonificación se determinó mediante la reflectancia media de la vitrinita, lo cual permitió identificar un aumento de rango con la profundidad. En cuanto a la composición maceral, esta se realizó de acuerdo a la clasificación del ICCP (Suárez et al., 2008) a fin de calcular los índices de gelificación, conservación de los tejidos, vegetación y presencia de aguas subterráneas, para el posicionamiento en los diagramas de (Diessel, 1986) y (Calder en Singh et al. 2000). Además se tuvieron en cuenta los diagramas ternarios propuestos por (Stach y Singh et al., 2000), que permiten determinar las condiciones oxidantes de la turbera y la tabla de agua. (Diessel, 1992; Calder et al., 1991 en Singh et al. 2000; Buillit et al., 2002; Smyth,
1979; Prasanta K. Mukhopadhyay et al., 1994 en Singh et al., 2000; Guatame et al., 2004).

\section{METODOLOGÍA}

Se recolectaron 64 muestras de carbón distribuidas aleatoriamente en tres secciones del flanco occidental del sinclinal Checua-Lenguazaque mediante el método de canal en frentes de explotación de diferentes minas subterráneas activas de acuerdo a la norma ASTM D 4596 - 99; 17 muestras para Sutatausa, 21 para Guachetá y 26 para Samacá, estas muestras se analizaron individualmente debido a que no pudo establecerse su continuidad lateral por la intensa actividad tectónica en el área. La preparación de las muestras se realizó de acuerdo a la norma ASTM D 3039 - 76 para la probeta pulida. Con el análisis de la reflectancia media de la vitrinita se clasificaron los carbones usando la norma ISO 11760.

Con los resultados de la lectura maceral de acuerdo a la nueva clasificación del ICCP (Suárez et al., 2008) se establecieron los indicies petrográficos, con los cuales se realizó un análisis numérico para la obtención de los ambientes depositacionales de la turba, además de la aplicación de diferentes diagramas ternarios que permiten determinar las condiciones oxidantes y de la tabla de agua en la turbera.

\section{DETERMINACIÓN DEL RANGO DEL CARBÓN}

El rango de los carbones se determina mediante la reflectancia de la vitrinita, y representa el grado de maduración desde la turba hasta la antracita. Este rango depende de la acción bioquímica sobre la materia vegetal y es influenciado en su gran mayoría por la presión y la temperatura en el proceso de enterramiento (American Society for Testing and Materials, 2000; Taylor et al., 1998; Uribe, 1986; Guatame et al., 2004). Para los carbones analizados es evidente como el rango aumenta con la profundidad, por lo cual los materiales encontrados presentan variación de sus propiedades como materia volátil, humedad y carbono fijo. La reflectancia media de la vitrinita fue de gran importancia pues permitió la clasificación de los carbones de acuerdo a la norma ISO 11760. Los resultados dieron como conclusión que los carbones muestreados variaron de bituminosos $\mathrm{C}$ a bituminosos A, como se observa en la Figura 2.

Rev. 12+D. Vol.16 N². Julio-Diciembre. 2016. Sogamoso-Boyacá, Colombia. 


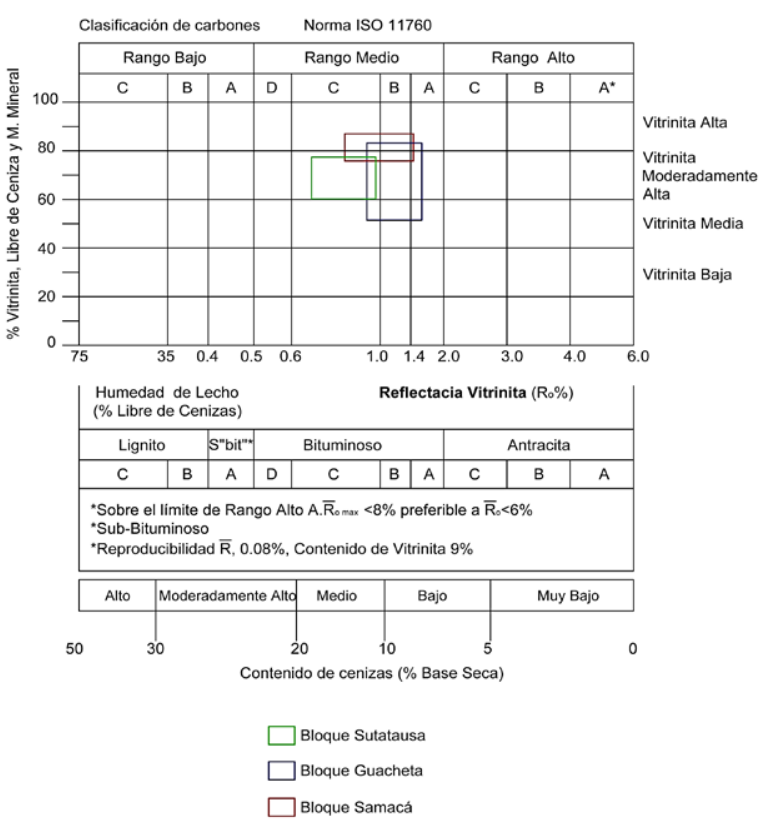

Figura 2. Clasificación de los carbones de la Formación Guaduas en el sinclinal Checua-Lenguazaque (Modificado Norma ISO 11760, 2000) de acuerdo al valor de reflectancia de la vitrinita.

\section{DESCRIPCIÓN PETROGRÁFICA}

\subsection{Identificación de Macerales}

Los macerales corresponden a los restos carbonificados de tejidos de las plantas o sustancias derivadas de las plantas existentes en el momento de la formación de la turba (Suárez et al., 2008). Los componentes orgánicos se dividen en tres grupos macerales, vitrinita-liptinitainertinita (Ver Clasificación en Suárez et al., 2008). En las 64 muestras analizadas pudo observarse que el grupo maceral predominante fue el de la vitrinita $(51.4 \%$ - 87\%) seguido por la inertinita $(5.4 \%-43.8 \%)$, y en proporciones menores el de la liptinita $(0.2 \%-14 \%)$ como se aprecia en la (Figura 3). La material mineral varió de $0.4 \%-18 \%$.

4.1.1 Vitrinita: Los carbones estudiados presentan abundancia de macerales del grupo de la vitrinita (Figura $3)$, esto indica que la materia vegetal originaria estaba compuesta predominantemente por lignina, celulosa y parcialmente de tanino y geles coloidales húmicos (Suárez et al., 2008). Sin embargo existe una tendencia fúsica relacionada a los procesos previos que sufrieron estos materiales en el momento de la depositación debido a la oxidación, o, alteraciones causadas por los agentes oxido-reductores y bioquímicos en la etapa de la turbera (Suárez et al., 2008). Los altos valores de vitrinita indican que la turbera se encontraba saturada de agua inhibiendo la oxidación de la turba (Nowak et al., 1999 en Guatame et al., 2004). La discriminación entre los diferentes macerales del grupo de la vitrinita permite dar una aproximación de la conservación de los tejidos (Rimmer et al. 1988 en Jimenez et al., 2007), así como algunos procesos físicos y químicos y tipo de material original a partir del cual se formó el carbón (Suárez et al., 2008).

Se encontró que los macerales predominantes fueron la colodetrinita y la colotelinita (Figura 4), el primero originado a partir del fuerte deterioro de los tejidos parenquimatosos y leñosos del tallo y las hojas originalmente compuestas de celulosa y lignina, mientras que el segundo se origina a partir de los mismos componentes pero conservados en mayor medida. Los altos valores de colodetrinita pueden asociarse a un elevado $\mathrm{Ph}$ y presencia de aguas frescas y oxigenadas que favorecen la degradación de los materiales, mientras que la abundancia de la colotelinita indica que la materia orgánica sufrió menos alteración debido a un ph más bajo y menor altura en la tabla de agua (Mukhopadhya 1994; Jimenez et al., 2007).

4.1.2 Liptinita: En las muestras analizadas las cantidades de liptinita fueron menores en comparación a los otros grupos macerales, sin embargo se presentaron concentraciones significativas de cutinita $(6,2 \%)$ y resinita $(4,4 \%)$ seguidas por las de esporinita, exudatinita, y liptodetrinita. La cantidad reducida de estos materiales se debe a la transformación térmica en el proceso de carbonificación (Suárez et al., 2008) ó a su desaparición relacionada posiblemente a la influencia de aguas salobres en el momento de la depositación (Taylor et al., 1998).

4.1.3 Inertinita: Corresponde a materia vegetal que fue fuertemente alterada y degradada en condiciones oxidantes antes de la depositación, o por condiciones oxido-reductoras, procesos bioquímicos y procesos químicos en la etapa de la turba (Suárez et al., 2008). Los macerales predominantes de este grupo fueron la micrinita producto de la carbonización, restos de lipoides y fuerte fragmentación de otras inertinitas; la semifusinita y la fusinita como se observa en la Figura 
4. Los menores contenidos de inertinita se encontraron en el bloque Sutatausa, lo cual indica mayor protección en el área de depositación debido a la disminución de la tasa de oxidación; así como pocos incendios forestales y periodos secos (Scott, 1989 en Alves et al., 1996; Nowak et al., 1999), además de indicar reducida exposición de los materiales a condiciones oxidantes o lapsos prolongados de meteorización (Guatame et al., 2004).

4.1.4 Materia mineral: Fue tenida en cuenta durante el conteo, para este caso se discriminó entre arcilla, cuarzo, pirita orgánica e inorgánica, y minerales de hierro, concluyéndose que existe predominancia de las arcillas, minerales de hierro y cuarzo respectivamente.

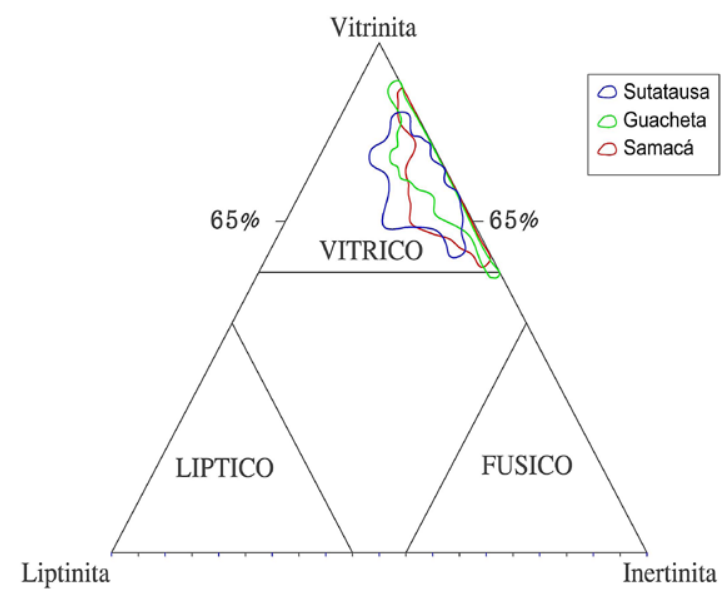

Figura 3. Tipo de carbón de acuerdo a la distribución de los grupos macerales (Modificado de Stach, 1982), donde se observa que los carbones son predominantemente Vítricos.

De acuerdo a la distribución de los componentes macerales se concluye que predominaron los del grupo de la vitrinita indicando que los carbones se depositaron en condiciones reductoras y de acuerdo a la proporción entre colotelinita y colodetrinita puede hacerse una primera aproximación a que la tabla de agua aunque variable permitió en gran medida la conservación de los componentes orgánicos.

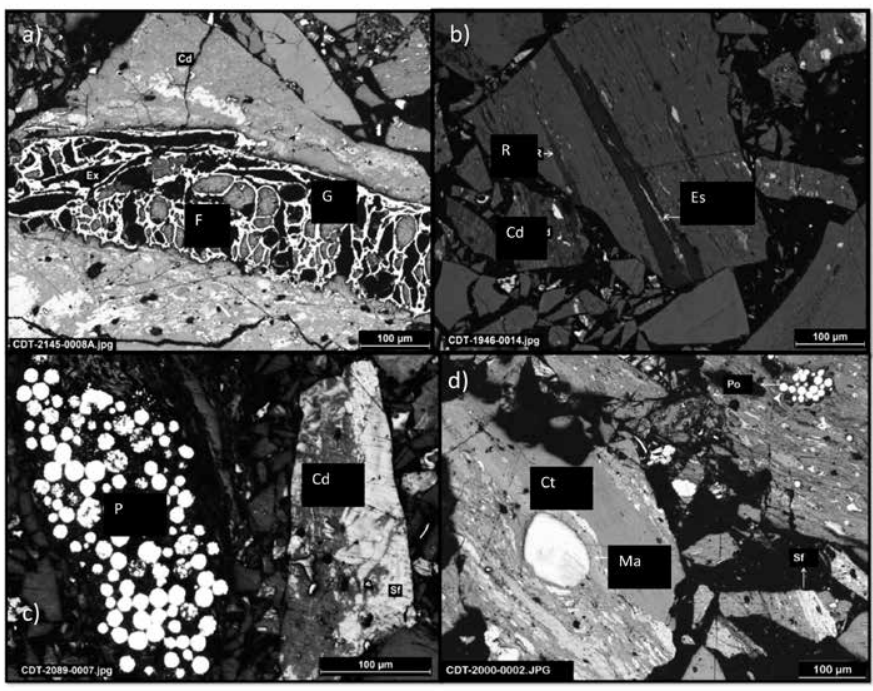

Figura 4. Microfotografías de los carbones de la Formación Guaduas, a) Gelinita (G) rellendando cavidad de Fusinita (F), manto Gemela Inferior (sección Samacá); b) Esporinita (Es) en una masa de colodetrinita (Cd), manto Chica 3 (sección Sutatausa); c) Pirita (P) de carácter orgánico, manto Perdida superior (sección Samacá); d) Macrinita (Ma) y banda de Colotelinita $(\mathrm{Ct})$, manto Bolas (Sección Guachetá).

\section{FACIES Y PALEOAMBIENTES DEPOSITACIONALES DE LOS CARBONES DE LA FORMACIÓN GUADUAS}

Mediante el reconocimiento de las facies en el carbón es posible asociarlas a diferentes ambientes sedimentarios, para este caso se usó netamente la lectura de composición maceral a fin de determinar índices petrográficos para determinar paleoambientes así como la ubicación en diagramas ternarios (Singh et al., 2000) que permitieron su asociación a diferentes condiciones ambientales durante la depositación.

\section{1 Índices Petrográficos}

Los índices propuestos por (Diessel, 1992), permiten ubicar las facies del carbón en el diagrama modificado posteriormente por (Alves \& Ade 1996). En estos determinan los parámetros TPI (Índice de preservación de los tejidos) y GI (índice de gelificación).

5.1.1 Índice de preservación de los tejidos: Muestra la relación entre los componentes orgánicos que están conservados mecánica y texturalmente y los que no lo están (Ecuación 1). (Diessel, 1992; Singh et al., 2000).

Rev. 12+D. Vol.16 N². Julio-Diciembre. 2016. Sogamoso-Boyacá, Colombia. 
Gómez-Neita, J.S., López-Carrasquilla, M.D., Manosalva- Sánchez, S.R., \& Naranjo-Merchán, W.E.

$T P I=\frac{\text { Telinita }+ \text { Colotelinita }+ \text { Semifusinita }+ \text { Fusinita }}{\text { Colodetrinita }+ \text { Macrinita }+ \text { Inertodetrinita }}$

(Modificado con la nueva clasificación del ICCP (Suárez et al., 2008))

5.1.2 Índice de gelificación: Este índice muestra la relación entre los componentes gelificados y oxidados, revelando un nivel aproximado de la tabla de agua (Ecuación 2) (Marchioni, 1994; en Guatame et al., 2004; Jimenez et al., 2007; Guatame et al., 2004).

$$
G I=\frac{\text { Vitrinita }+ \text { Macrinita }}{\text { Semifusinita }+ \text { Fusinita }+ \text { Inertodetrinita }}
$$

(Modificado con la nueva clasificación del ICCP (Suárez et al., 2008))

De acuerdo al diagrama propuesto por (Diessel, 1992), el cual relaciona el índice de gelificación con el índice de preservación de los tejidos para la determinación del ambiente de depositación; se deduce, que los carbones de la Formación Guaduas se depositaron en condiciones limno-telmáticas a telmáticas predominando la primera condición propuesta, en ambientes afectados por transgresiones en llanuras costeras principalmente corroborando los resultados obtenidos por (Guatame et al., 2004). Los carbones de Samacá y Guachetá presentan una disposición preferencial con valores medios a altos de $\mathrm{Gl}$ asociados a una mayor proporción de componentes gelificados frente a los oxidados; y bajos valores de TPI debido a la presencia dominante de colodetrinita producto de un incremento de la humificación en la turba y un aumento significativo en el transporte de partículas (Guatame et al., 2004). Sin embargo para el bloque Sutatausa se observa mayor dispersión en los datos debido a la variación en los parámetros que forman el índice TPI, el cual en algunos carbones indica que hubo mayor conservación de los tejidos debido a la abundancia de colotelinitas, fusinitas y semifusinitas. Con base en los resultados obtenidos se concluyó que estos carbones fueron depositados en diferentes ambientes parálicos, como ciénagas, llanuras costeras, llanuras deltáicas y pantanos de bosque húmedo como se observa en la Figura 5.

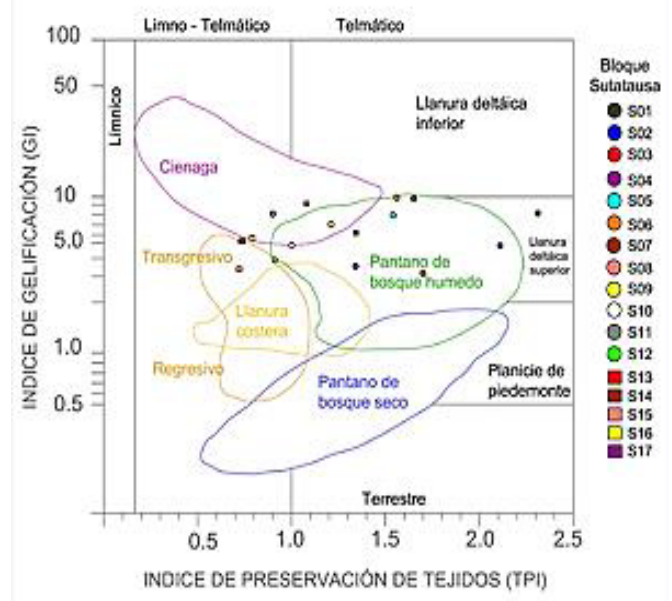

a)

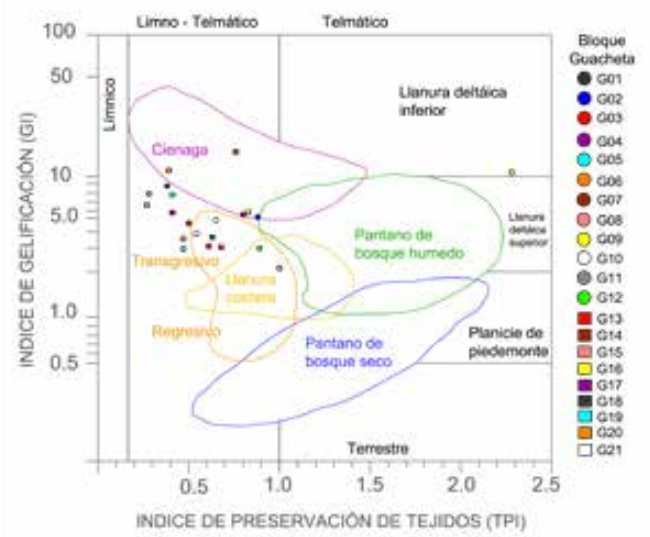

b)

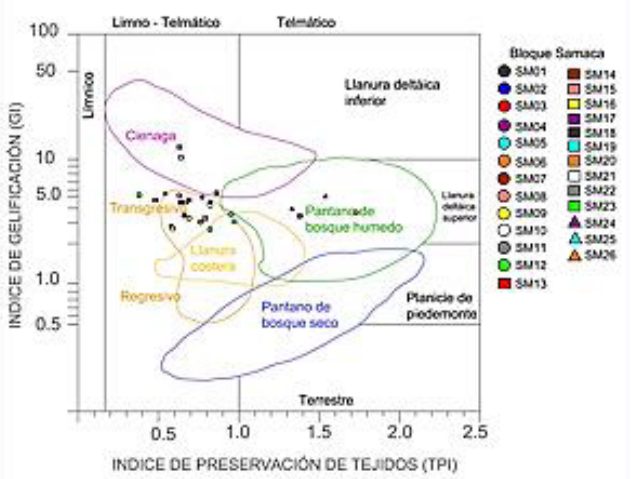

c)

Figura 5. Diagrama de Facies de los carbones de la Formación Guaduas, con base a los Índices de (Diessel, 1992) (TPI y GI), modificado por (Alves et al., 1996). Las imágenes corresponden respectivamente: a) bloque Sutatausa, b) bloque Guachetá, c) bloque Samacá, donde se aprecia la distribución de los carbones en el ambiente y facies correspondiente de acuerdo a los índices obtenidos de cada manto. 
Por otra parte, (calder et al., 1991; Singh et al., 2000) proponen los indices VI (indice de vegetacion) y GWI (indice de aguas subterraneas), donde a partir de estos valores pueden asociarse condiciones ambientales de la turbera y permiten de manera general dar la ubicación relativa de la turbera y la influencia del agua en esta, complementando la informacion ambiental provista mediante los índices de Diessel.

5.1.3 Indice de Vegetación: Este índice relaciona los macerales de afinidad boscosa con los de afinidad herbácea y acuática (Ecuación 3) (Calder et al., 1991 en Guatame et al., 2004; Jimenez et al., 2007) denotando que para la zona de estudio predomianron las plantas herbáceas.

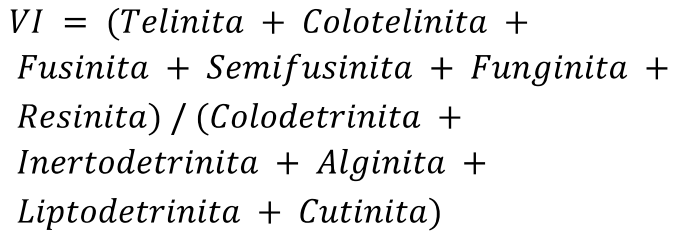

(Modificado con la nueva clasificación del ICCP (Suárez et al., 2008))

5.1.4 Indice de Aguas Subterráneas: Este índice establece el contraste de macerales fuertemente gelificados con los que no lo son (Ecuación 4) (Calder et al., (1991) en Jimenez et al., 1999; Guatame et al., 2004), indicando el nivel relativo del agua en la turbera o pantano.

$$
G W I=
$$

Gelinita+Corpogelinita+Materia Mineral+Vitrodetrinita Telinita+Colotelinita+Colodetrinita

(Modificado con la nueva clasificación del ICCP (Suárez et al., 2008))

Para este caso la mayoría de los carbones fueron depositados en condiciones ombotróficas y oligotróficas debido a los bajos valores de VI (indice de vegetacion) donde la vegetación predominante correspondía a juncos. Sin embargo, algunos de los carbones especialmente los de la sección Sutatausa (como se observa en la Figura 6) se ubican un poco mas cerca de las zonas donde predominan plantas boscosas con tendencia a condiciones mesotróficas. La predominancia de condiciones ombotróficas índican un ambiente aislado en el cual de acuerdo al tipo de vegetación se evidencia la presencia de pantanos y, pocos nutrientes lo que ínhibio la formación de grandes bosques.

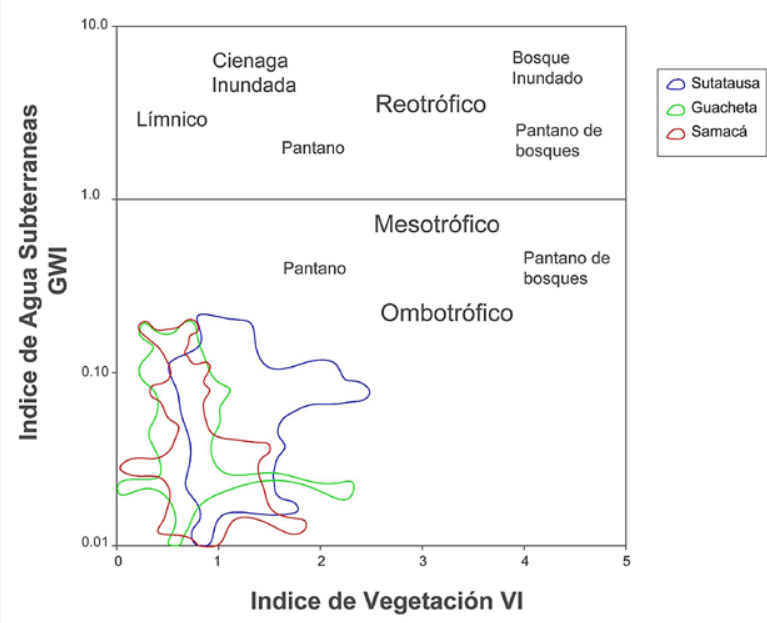

Figura 6. Diagrama de paleoambientes de la turbera de la Formación Guaduas, propuesto por (Calder et al., 1991 en Singh et al., 2000). Se determina una condición ombotrófica generalizada para los carbones de los tres bloques analizados.

\subsection{Diagramas Ternarios Para Determinación de Facies}

(Mukhopadhyay, 1994 en Guatame et al., 2004; Singh et al., 2000), propone un diagrama ternario para la determinación de facies a partir de la asociación maceral de la siguiente forma:

A: Vitrinita (Telovitrinita + Colodetrinita + Gelovitrinita) + Exinita terrestre (indica de manera general buena preservación en los tejidos originales).

B: Vitrodetrinita + Liptodetrinita + Gelocolinita (define mayor maceración, actividad bacterial incrementando la anoxicidad).

$C$ : Inertinita (señala condiciones secas).

$D$ : Pantanos de bosques ligeramente óxicos con buena preservación de los tejidos.

E: Ciénagas de juncos. Incrementa la maceración y actividad bacteriana, incremento anóxico.

F: Condiciones óxicas. (Secas)

De acuerdo a los resultados obtenidos como se observa en la Figura 7, existe una clara tendencia que indica que los carbones de la Formación Guaduas en el flanco occidental del sinclinal Checua-Lenguazaque fueron depositados en pantanos de bosques ligeramente óxicos

Rev. I2+D. Vol.16 N². Julio-Diciembre. 2016. Sogamoso-Boyacá, Colombia. 
con buena preservación de los tejidos, con tendencia a ciénagas (bloque Sutatausa); donde existe mayor actividad bacterial y por ende mayor maceración de los componentes orgánicos.

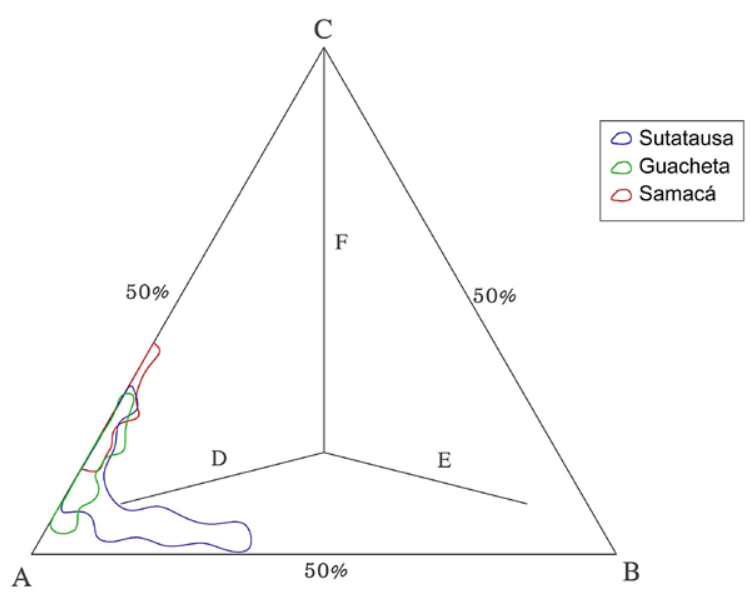

Figura 7. Facies de los carbones de la Formación Guaduas de acuerdo con la composición maceral, propuesto por (Singh et al., 2000), se establece una depositación en pantanos de bosque ligeramente óxicos.

Así mismo (Singh et al., 2000), utilizan el diagrama propuesto en la Figura 8, para determinar a partir de las proporciones entre algunos grupos macerales y materia mineral las condiciones de oxidación del ambiente. Para este caso puede observarse que los carbones fueron depositados en pantanos óxicos-anóxicos o en pantanos húmedos con moderada a alta inundación (especialmente en la seccion Guachetá); no obstante ninguno de los carbones se desarrollo en condiciones totalmente óxicas debido a que no se observaron proporciones dominantes de materia mineral o inertinita, lo cual índica que la tabla de agua aunque fue variable no estuvo ausente y por ende hubo una mayor concentración y conservación de la materia orgánica. Los resultados pueden indicar lo siguiente:
A: Alternancia de pantanos óxicos y anóxicos.

E: Pantanos óxicos con repentina a alta inundación.

F: Pantano húmedo con intermitente y moderada a alta inundación.

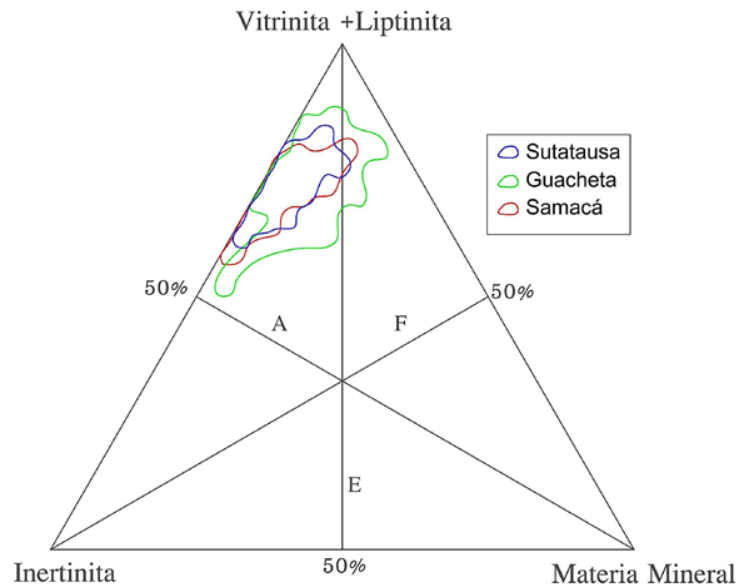

Figura 8. Condiciones deposicionales de los carbones de la Formación Guaduas, propuesto por (Singh et al,. (2000). Se identifica una alternancia entre pantanos óxicos a anóxicos predominantemente.

Otro diagrama usado por (Singh et al., 2000) (Figura 9) permite analizar facies del carbón de acuerdo al análisis cuantitativo de los macerales del grupo de la liptinita. A partir de éste, se determinó que los carbones de los tres bloques fueron depositados en pantanos dominados por juncos y en una transición entre pantanos boscosos y pantanos de juncos en donde hubo variaciones en la profundidad del agua de acuerdo al aumento del contenido de esporinita y cutinita. Los bajos valores de alginita $(<0.1 \%)$ indican que la materia orgánica dominante es de origen terrestre, debido a esto las incursiones marinas fueron de poco nivel y por tanto no permitieron el desarrollo de materia vegetal marina aunque resultaron importantes porque permitieron la variación en la tabla de agua. 


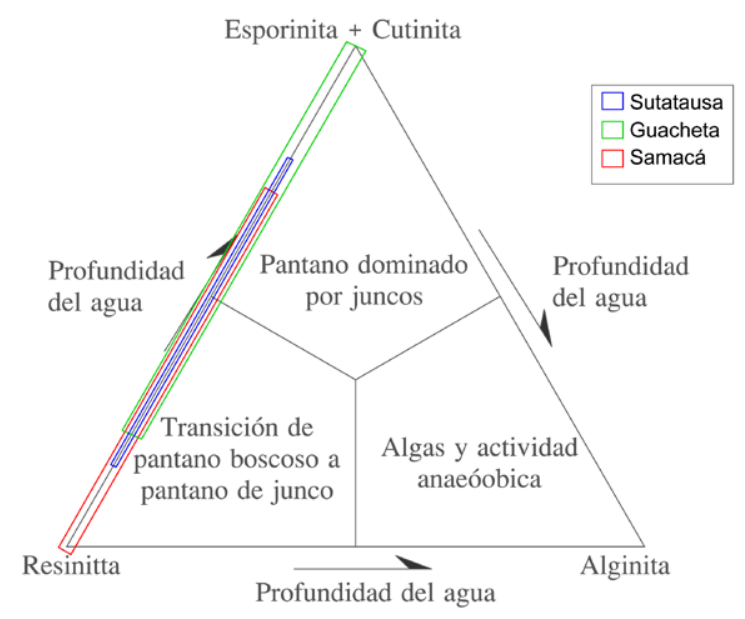

Figura 9. Diagrama Ternario donde se muestran las facies de los carbones y las condiciones de profundidad del agua (Modificado de Mejía et al.,2006; y de Singh et al., 2000), basados en la proporción de los macerales del grupo de la Liptinita, se evidencia que los carbones fueron depositados en pantanos dominados por juncos, siendo esta condición general para los tres bloques de estudio.

\section{INTERPRETACIÓN DE LOS PALEOAMBIENTES DE LOS CARBONES DE LA FORMACIÓN GUADUAS A PARTIR DEL ANÁLISIS MACERAL}

Los macerales presentes en el carbón son consecuencia directa de los ambientes de formación de éste, modificados por los efectos post-depositaciones en el proceso de carbonificación. Los estudios petrográficos detallados permiten conseguir información valiosa de las facies del carbón en el momento de la depositación (Mejía et al., 2006).

Los carbones de la Formación Guaduas se acumularon en facies de ambientes transicionales con ocasionales incursiones marinas las cuales permitieron una condición saturada de los materiales y por ende una mayor conservación de la materia orgánica. Estos materiales se depositaron en ambientes telmáticos (terrestres) a límnicos (subacuáticos) (Guatame et al., 2004). Se determinaron diversos ambientes como cienagas, llanuras costeras, llanuras deltáicas y pantanos de bosque humedo, los cuales estuvieron protegidos de las aguas del mar como se observa en la Figura 10.

Los mantos de carbón presentaron diferentes comportamientos; donde los resultados obtenidos permitieron determinar los siguientes aspectos:

a) Los carbones a lo largo del sinclinal de ChecuaLenguazaque presentan dominantemente macerales del grupo de la vitrinita, lo cual indica que hubo buen aporte de materia organica y conservacion de esta.

b) La materia orgánica se acumuló en ambientes de Ciénagas y llanuras costeras principalmente en los bloques Guachetá y Samacá, mientras que en Sutatausa presenta una disposición mas abierta hacia bosques de pantanos húmedos; en ambas situaciones hubo importancia de las incursiones marinas.

c) Los carbones para los tres bloques se depositaron en condiciones ombotróficas, es decir que tanto el agua como los nutrientes provienen de las precipitaciones. Para el bloque Sutatausa se observa una leve tendencia entre condiciones ombotróficas a mesotróficas donde existe una cantidad moderada de nutrientes.

d) Se observa una disposición preferencial en la composición maceral de los tres bloques indicando que estos carbones fueron depositados en pantanos de bosques húmedos ligeramente óxicos o pantanos de juncos con mayor maceración.

e) Los carbones en cuestión se depositaron en Alternancia de pantanos óxicos y anóxicos y en pantanos húmedos con intermitente $y$, moderada a alta inundación.

f) Los materiales se acumularon en pantanos boscosos, pantanos dominados por juncos y en la trancision entre estos dos. De acuerdo a (E. Stach, 1982) las condiciones deposicionales de los carbones deben ser tranquilas en una cuenca con subsidencia constante y un régimen tectónico estable (Mejía et al., 2006). 


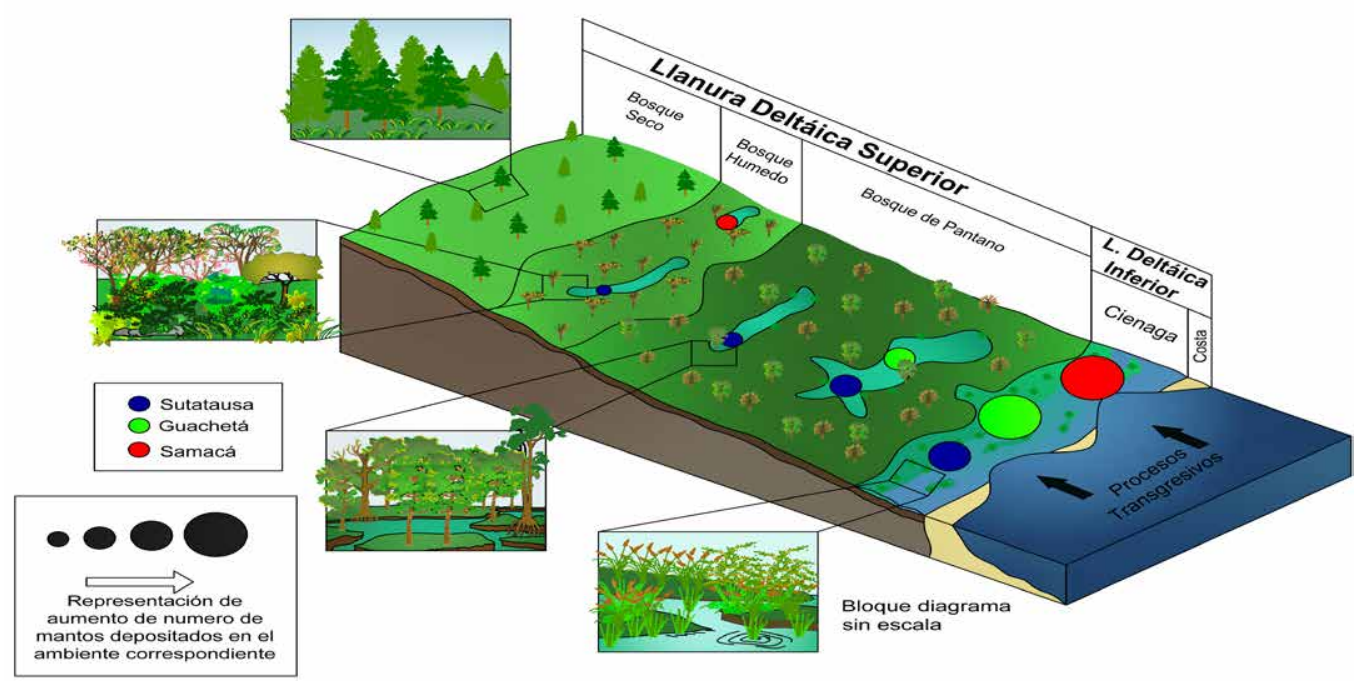

Figura 10. Paleoambientes de lo carbones de la Formación Guaduas en el sinclinal Checua-Lenguazaque (modificado Guatame et al ., 2004). Se aprecia que los carbones en el bloque Sutatausa presentan mayor dispersion referente a los ambientes de depositación. El posicionamiento en este diagrama es una forma representativa de ilustrar su ubicación pero no indica que la depositación fue simultanea. El bloque Guachetá muestra una disposición mas uniforme indicando que los carbones se desarrollaron posiblemente en ambientes paralicos mas cercanos a la costa (Cienagas). El bloque Samacá muestra un resultado similar al del bloque Guachetá, indicando que en estos sectores las condiciones depositacionales fueron similares.

\section{CONCLUSIONES}

En el flanco occidental del sinclinal ChecuaLenguazaque, las condiciones para la acumulación de la materia orgánica fueron óptimas, donde los bloques Samacá y Guachetá, se caracterizan por un desarrollo en ambientes parálicos de ciénagas, llanuras costeras y eventualmente en pantanos de bosque; sin embargo, las características varían para el bloque Sutatausa, donde la acumulación se generó en ambientes con una disposición más abierta hacia bosques de pantanos húmedos debido a un cambio marcado principalmente en los macerales del grupo de la vitrinita (colotelinita y colodetrinita), lo que refleja que para este sector las condiciones de depositaciòn fueron diferentes como puede evidenciarse en los diferentes diagramas.

El análisis petrográfico permitió establecer que los macerales del grupo de la vitrinita son el componente principal de los carbones de esta región con porcentajes entre $(51.4 \%-87 \%)$, seguido por los de la inertinita; permitiendo deducir que la vegetación dominante fue herbácea a arborescente; bien conservada y protegida de los procesos oxidantes como lo describió (Guatame et al., 2004).
Con base en la propuesta de Singh \& Singh (2000), donde a partir de la asociación maceral se puede determinar las facies de depositación; se estableció que los carbones de la Formación Guaduas en el sinclinal Checua-Lenguazaque fueron depositados en pantanos de bosques ligeramente óxicos con buena preservación de los tejidos, con tendencia a ciénagas (bloque Sutatausa) donde existe mayor actividad bacterial y por ende mayor maceración de los componentes orgánicos, lo cual indica junto a los demás resultados que las condiciones en el sector Sutatausa fueron diferentes como se mencionó anteriormente.

El cálculo del índice de agua subterránea e índice de vegetación y la ubicación en diferentes diagramas ternarios (Singh et al., 2000), permitió establecer que aunque la tabla de agua fue variable, esta generalmente cubría la turbera, por lo que inhibió los procesos de oxidación que hubiesen sido mayores en zonas secas o con condiciones más oxidantes, evidenciado en una distribución diferente de los grupos macerales. La relación de los valores de índice de agua subterránea (GWI) y el índice de vegetación (VI), muestran que la turbera se originó en un ambiente de pantano bajo condiciones ombrotróficas en turberas alimentadas por precipitaciones y que debido a los escasos nutrientes no hubo abundante desarrollo de vegetación boscosa. 
El análisis de reflectancia media a la vitrinita permitió establecer las variaciones del rango del carbón con el aumento de la profundidad (carbones bituminosos $C$ a carbones bituminosos A), lo cual concuerda con el aumento de las condiciones de temperatura y presión con el enterramiento.

\section{AGRADECIMIENTOS}

Se dan agradecimientos a las empresas MINAS $Y$ MINERALES S.A, S.I. CARBOCOQUE, S.I. MILPA S.A y CDT MINERAL por permitir realizar el muestro y facilitar las herramientas pertinentes para el mismo. A la doctora Isabel Suarez (ICCP- España) por su colaboración con las últimas actualizaciones del comité y a Clara Liliana Guatame por su asesoría. Esta publicación es producto del proyecto: Caracterización petrográfica y fisicoquímica de los carbones coquizables de la Formación Guaduas, bases para el modelamiento geológico y optimización del recurso. Realizado por el grupo de investigación de la escuela de Ingeniería Geológica con el apoyo de COLCIENCIAS.

\section{REFERENCIAS}

Alves, R. G., \& Ade, M. V. B. (1996). Sequence stratigraphy and coal petrography applied to the Candiota Coal Field, Rio Grande do Sul, Brazil : A depositional model, 30, 231-248.

Amaya, E. (2010). Litofacies y ambientes de acumulación de la Formación Guaduas en la parte central de la cordillera oriental -, 32, 13-25. Boletín de Geología -UIS.

American Society for Testing and Materials (ASTM). (2000). Standard Classification of Coals by Rank (ASTM D388-15). In STANDARD.

Cooper, M., Addison, F., Alvarez, R., Coral, M., Graham, H., Hayward, B., Howe, S., Martinez, J., Naar, J., Peñas, R., Pulham, A,J., Taborda, A. 1995. Basin development and tectonic history of the Llanos Basin, Eastern Cordillera, and Middle Magdalena Valley, Colombia. A.A.P.G Bulletin , 14211443.
Diessel, C. F. (1992). Coal-Bearing Depositional Systems (1s ed.). Berlin Heidelberg New York: Springer-Verlag, pag 161-264.

E. Stach, T. b.-T. (1982). Coal Petrology. Berlin- Stuttgart: Gebruder Borntraeger, 535 pp.

Guatame, C. L., \& Sarmiento, G. (2004). Interpretación del Ambiente Sedimentario de los Carbones de la Formación Guaduas en el Sinclinal Checua-Lenguazaque a partir del Análisis Petrográfico. Geología Colombiana, (29), 41-57.

Jimenez, A., Laggoun-d, F., \& Suarez-ruiz, I. (2007). Study of physical and chemical properties of vitrinites . Inferences on depositional and coalification controls Study of physical and chemical properties of vitrinites. Inferences on depositional and coalification controls, $35 \mathrm{pp}$.

Mejía-umaña, L. J., Convers-gómez, C. E., \& González-casallas, J. F. (2006). Análisis de Microlitotipos en los Carbones de la Formación Guaduas en el Sinclinal de Sueva, Cundinamarca Coal Microlithotype analysis of the Guaduas Formation in the Sueva Syncline, Cundinamarca , Colombia, (31), 11 ?26.

Norma ISO 11760. (2000). International Standard. Test, 2000. http://doi.org/10.5594/J09750.

Nowak, G. J., \& Górecka-Nowak, A. (1999). Peat-forming environments of Westphalian A coal seams from the Lower Silesian Coal Basin of SW Poland based on petrographic and palynologic data. International Journal of Coal Geology, 40(4), 327-351. DOI: http://doi.org/10.1016/ S0166-5162(99)00007-5.

Prasanta K. Mukhopadhyay, W. G. (1994). Vitrinite reflectance as Maturity parameter: petrographic and Molecular Characterization and its implication to Basin Modeling (vol 570 ed.). American Chemical Society, p. 140.

Singh, M. P., \& Singh, A. K. (2000). Petrographic characteristics and depositional conditions of Eocene coals of platform basins ,. International Journal

Rev. I2+D. Vol.16 N² 2. Julio-Diciembre. 2016. Sogamoso-Boyacá, Colombia. 
Gómez-Neita, J.S., López-Carrasquilla, M.D., Manosalva- Sánchez, S.R., \& Naranjo-Merchán, W.E.

of Coal Geology, (Received 23 June 1998; accepted 30 July 1999), 315-356.

Suárez-Ruiz, I., \& Ward, C. R. (2008). Basic Factors Controlling Coal Quality and Technological Behavior of Coal. Applied Coal Petrology, (1), 19-59. DOI: http://doi.org/10.1016/B978-0-08-0450513.00002-6

Taylor, E. G., Teichmüller, M., Davis, A., Diessel, C., Littke, R., \& Robert, P. (1998). Organic Petrology. Berlin- Stuttgart: Gebruder Borntraeger, 704pp. 